\title{
寒天からアガロースとアガロペクチンの分離 ${ }^{*}$ \\ 林金 雄**平 光 武***
}

Separation of Agarose and Agaropectin from Agar

Kaneo Hayashi and Takeshi Hiramitsu

\begin{abstract}
Agar were prepared from the material seaweed for agar industry, i.e. Gelidium amansii, Gelidium japonicum, Ceramium boydenii and Gracilaria verrucosa, to separate agarose and agaropectin by the methods of acetylation, sodium iodide and dimethylsulfoxide.

It was found that the ratio of agarose and agaropectin varied with the kind of seaweed employed as raw material, the method of preparation of agar and the method of separation of them.

The content of D-galactose and 3,6-anhydro-L-galactose in agarose obtained was found to be $49-50 \%$ and $44-54 \%$ respectively. The infrared spectrum of agar, agarose and agaropectin was considered to be approximately identical.
\end{abstract}

寒天は中性多糖類のアガロース (AG) と酸性多糖類の フガロペクチン (AP) からなっているが，不均一なもの であって，酸性成分含量の非常に少ないるのふら多い

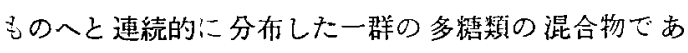
る1)。

そして $\mathrm{AG}$ :こついては荒木らの研究によって, その 化学構造ぶ明らう:なったが，APについては未解明の 点が多い。

AG と AP の分離法としてはフセチル化法9!・ジメチ ルスルホキシド(去4-6) ・ヨウ化ナトリウム汒7および塩化 セチルピリジニウム法8) などが試みられているが，分離 の実施方法や実施中の変化などについては笕明すべき点 が少なくない。

著者らは，4種類の代表的な寒天製造原藻を用いて調 製した寒天から AG および AP 分分嶉し、これらにつ いて比皎検討したので報告する。

\section{実験および結果}

\section{1. 供試原藻}

第 1 表に示した 4 種類の原藻を使用した。

\section{2. 寒穴の調製と理化学的性質}

(1) マクサ，オニクサおよびナミクサ方ら寒天の調製 宗藻 $120 \mathrm{~g}$ を $5 l$ の三角フラスコにとり，30 倍量の

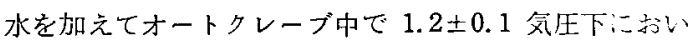
て、マクサ，フミクサでは 90 分，オニクサでは 120 分 煮熟し，ナイロン沪布（足立瀻維製ナイロン NF 1001 沪布）2枚で沪過し，さらに圧控器で圧控する。沪液は

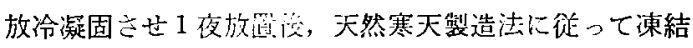
融解および脱水を行ない乾懆した。収率（原藻無水物に 刘する寒天無水物％)泣，マクサ 43\%，オ二クサ $35 \%$ ， フミクサ $30 \%$

(2)オゴノリから寒天の調裂

第 1 表 供 試 原 藻

\begin{tabular}{|c|c|c|c|c|}
\hline 原 & 乘 & 操取地 & 採取年月 & 水分 $(\%)$ \\
\hline マクサ & Gelio'ium amansii & 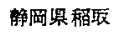 & $1968 \cdot \mathrm{VI}$ & 16.8 \\
\hline オニクサ & Gelidium jabonicum & 闻贯需見 & $1968 \cdot \mathrm{VI}$ & 14.3 \\
\hline Tミクサ & Ceramium boydenii & 石川県珠洲 & 1968 · Vili & 15.7 \\
\hline オゴリ & Gracilaria verrucosa & 北海道厚岸 & $1967 \cdot \mathrm{XI}$ & 15.0 \\
\hline
\end{tabular}

* 岐阜県における寒天製造に関する化学的研究（第 35 報）

** 汥阜大学農学部農芸化学科 (岐阜県各務原市那加門前町)

Faculty of Agriculture, Gifu University. Kakamigahara, Gifu.

****舫阜県寒天研究所（岐阜県恵那郡山岡町）

Gifu Research Institute of Agar-Agar. Yamaoka, Gifu. 
第 2 表 寒天の化学分析 （対筑水物\%)

\begin{tabular}{|c|c|c|c|c|c|}
\hline 䛿 & 科寒 & 天 & 水 分 & 灰 & 全 $\mathrm{SO}_{8}{ }^{*}$ \\
\hline$\rightarrow$ & $\eta$ & $\forall$ & 16.9 & 3.1 & 1.6 \\
\hline 才 & $=1$ & リ & 16.9 & 2.4 & 1.9 \\
\hline オ & $=D$ & \# & 18.1 & 2.6 & 1.8 \\
\hline 7 & $\Sigma \quad \eta$ & + & 15.9 & 3.6 & 1.3 \\
\hline
\end{tabular}

*既報の方法ぎに従って定篮しさ

第 3 表 寒天の物 性

\begin{tabular}{|c|c|c|c|c|c|c|c|}
\hline 試 & 科 & 宛 & 天 & $\begin{array}{c}\text { ゲル化点 } \\
\left.{ }^{\circ} \mathrm{C}\right)\end{array}$ & ${ }^{\left.{ }^{\circ} \mathrm{C}\right)^{\circ}}$ & $\begin{array}{c}*=y 一 \text { 柿度 } \\
\left(\mathrm{g} / \mathrm{cm}^{2}\right)\end{array}$ & $\begin{array}{l}\text { 奜慗 水 } \\
(\mathbf{g})\end{array}$ \\
\hline$\checkmark$ & $\Rightarrow$ & & + & 34.0 & 94 & 530 & 0.43 \\
\hline オ & $=$ & $\Rightarrow$ & $\forall$ & 36.0 & 98 & 943 & 0.43 \\
\hline 7 & $\Sigma$ & $\Rightarrow$ & \# & 38.0 & 84 & 720 & 1.04 \\
\hline
\end{tabular}

$400 \mathrm{~kg}$ のオゴノリを $6 \%$ カセインーダで $90^{\circ} \mathrm{C} ・ 4$ 時間フルカリ処理後, 酢酸 $6 l$ と塩化カルシウム $15 \mathrm{~kg}$

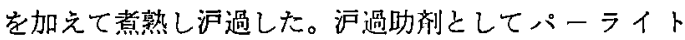
$100 \mathrm{~kg}$ ，漂白绪としてスターリット $2 \mathrm{~kg}$ 它加えた。以 下, 工業寒天の 圧力脱水法によって粉未寒天を調製し た。

\section{(3) 寒天の理化学的性質}

(a) 化学分析

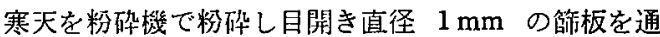
したもの岩試料として，符 2 表の結果を得た。灰分は，

2.4〜3.6\%， $\mathrm{SO}_{8}$ は 1.3〜1.9\%であった。オゴノリは アルカリ処理をしたものであるから灰分も $\mathrm{SO}_{8}$ もあま り高い值を示していない。

(b) 物性

次のような方法によって 2 ・3 の物性を測定した結果 は第 3 表のようで，試料寒天によってそれぞれの物性に かなりの差が誌奶れた。

ゲル化点： $1.5 \%$ の寒天溶液 $5 \mathrm{ml}$ を内径 $15 \mathrm{~mm}$ の 試験管に入れコルク栓を付し $50^{\circ} \mathrm{C}$ の恒温水槽に 30 分 間放置する。次に電源を切り $0.5^{\circ} \mathrm{C}$ 下がるごとに凝固 状態を調バ，凝固して動かなくなったときの温度を求め た。

瀜点：林らの方法101によった。

ジェリー強度：林らの方法 ${ }^{11)}$ によった。

離浆水: $1.5 \%$ 寒天溶液 $50 \mathrm{ml}$ を内径 $30 \mathrm{~mm}$ の試 験管に入れ，寒天液があふれ出ない程度に水平近く傾斜 させ，凝固後器壁およびゲル表面の㠜繀水を脱脂綿でぬ ぐいとり，コルク栓を付して $20^{\circ} \mathrm{C} に 3$ 日間同し傾斜
で静置し，離獎した水分を脱脂綿に吸着させて 科量し た。

\section{AG および AP の分離}

供試料として寒天を粉砝機で粉砕し，これをさらに石 臼で細粉としたものを用いた（粗寒天Ｉとする）

(1) フセチル化 (Ac) 法

粗寒天 I 10〜20 g について，荒木の方法"日従いピ リジン一無水酢酸 (1.5：1) を使用してアセチル化してア セチル化寒天 (AcAgar) をつくり，乙の AcAgar から $\mathrm{AcAG}$ と AcAP を分蚹し，さらにそれぞれから AG と AP を分離した。しかし第 5 表に示したよらに AcAgar の収量が少なかったので，寒天の精製を試みた。すなわ ち $3 \%$ 寒天溶液堂湯浴中で完全に加熱溶解後, $40^{\circ} \sim 50^{\circ}$ Cに温度を下げてから 3 倍量のアセトンを加えてよく 攪拌すると沈澱を生じる。1 夜放置後吸引沪過して沈澓 $\left(\mathrm{P}_{1}\right)$ と汇液 $\left(\mathrm{F}_{1}\right)$ とに分けた。沈澱 $\left(\mathrm{P}_{1}\right)$ 定アセトンで よく洗浄後, さらにアルコールとエーテルで処理乾燥し た（精製寒天とする）沪液 $\left(\mathrm{F}_{1}\right)$ は減生浱縮して, 再び アセトンを加えて沈澱 $\left(\mathrm{P}_{2}\right)$ と沪液 $\left(\mathrm{F}_{2}\right)$ に分け，沈溉 $\left(\mathrm{P}_{2}\right)$ 注沈澱 $\left(\mathrm{P}_{1}\right)$ と同様に処理した（粗寒天 II）。なお 沪液 $\left(\mathrm{F}_{2}\right)$ は再び減止濃縮してから蒸発血に移し, 湯浴 上で蒸発乾固した(固形物)。これらについての分析結果 は第 4 表のようで, 精製によって $\mathrm{SO}_{3}$ 含有量のやや多い 多糖類の部分およびその他の多糖類の 1 部が分離される ものと推定される。

精製寒天について上記の方法でてセチル化を試みたと ころ，第 5 表に示したようにアセチル化は良好となり， オゴノリでは差は認められなかったが，マクサとオニク サでは精製した場合のほらが AG の比率が高くなった。

なお同一原澡から調製した寒天でも調製法によって $\mathrm{AG}$ と AP の比率その他に差があることを第 6 表に示し た。

(2) ヨウ化ナトリウム (NaI) 法

布施らの方法7に準じて行なった。試料寒天粉末（タ

第 4 表 寒天の精製と分析 （対水\%）

\begin{tabular}{|c|c|c|c|c|c|c|c|}
\hline \multirow{2}{*}{ 供部寒天 } & \multirow{2}{*}{$\begin{array}{c}\mathrm{SO}_{3} \\
\mathrm{~A}\end{array}$} & \multicolumn{2}{|c|}{ 精䌘寒天 } & \multicolumn{2}{|c|}{ 粗寒天 II } & \multicolumn{2}{|c|}{ 全固形物 } \\
\hline & & 収率*1 & $\mathrm{SO}_{8}$ & 收事*1 & $\mathrm{SO}_{3}$ & 収率*1 & $\mathrm{SO}_{3}$ \\
\hline$\checkmark, \forall$ & 1.6 & 59 & 1.2 & 33 & 2.2 & 1.6 & 4.7 \\
\hline オ二クサ & 1.8 & 79 & 1.2 & 10 & 7.9 & 0.2 & 3.1 \\
\hline$オ ت ゙ / \nu$ & 1.9 & 99 & 1.7 & - *3 & - & 0.6 & 4.9 \\
\hline フミクサ & 1.3 & 71 & 1.2 & 27 & 3.1 & 0.6 & 2.2 \\
\hline
\end{tabular}

*1 俎寒天Iに対する\%

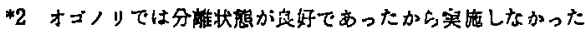


第 5 表 $A G$ と $\mathrm{AP}$ の分離

（対 無水物\%)

\begin{tabular}{|c|c|c|c|c|c|c|c|c|c|c|c|c|}
\hline & \multirow{2}{*}{ 試 料 } & \multirow{2}{*}{ 篒 } & \multirow{2}{*}{ 天 } & \multirow{2}{*}{ AcAgar*2 } & \multirow{2}{*}{$\mathrm{AcAG}^{* 3}$} & \multirow{2}{*}{$\operatorname{AcAP} * 3$} & \multicolumn{2}{|c|}{ 比 } & \multicolumn{2}{|c|}{$\mathbf{A G}$} & \multicolumn{2}{|c|}{$\underbrace{A P}$} \\
\hline & & & & & & & $A G$ & $\mathrm{AP}$ & $A G^{* 5}$ & $\mathrm{SO}_{3}$ & AP*b & $\mathrm{SO}_{3}$ \\
\hline \multirow[t]{2}{*}{$\checkmark$} & $\Rightarrow$ & サ & $($ 精) $* 1$ & 109 & 45 & 54 & 45 & 55 & 34 & 0.6 & 40 & 2.2 \\
\hline & $\prime \prime$ & & (啨) $* 1$ & 128 & - 49 & 34 & 59 & 41 & 38 & 0.4 & 28 & 0.9 \\
\hline \multirow[t]{2}{*}{ オ } & $=\eta$ & サ & (粨) & 118 & 39 & 58 & 40 & 60 & 31 & 0.3 & 43 & 1.7 \\
\hline & $\prime \prime$ & & (精) & 126 & 57 & 30 & 66 & 34 & 39 & 0.5 & 14 & 0.5 \\
\hline \multirow[t]{2}{*}{ オ } & $=1$ & ) & (租) & 114 & 81 & 12 & 87 & 13 & 52 & 0.4 & 7 & 3.1 \\
\hline & $" \prime$ & & (棈) & 134 & 72 & 17 & 81 & 19 & 53 & 0.4 & 15 & 2.9 \\
\hline 7 & 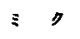 & $\forall$ & (啨) & 137 & 81 & 3 & 96 & 4 & 70 & 0.7 & 2 & - \\
\hline
\end{tabular}

*1 粗: 粗寒天I 精: 精製寒天

*2 鞑料寒天に対するてセチル化寒天の\%

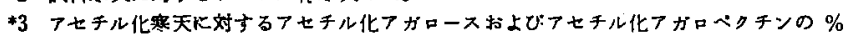

*4 $\mathrm{AG}=\frac{\mathrm{AcAG}}{\mathrm{AcAG}+\mathrm{ACAP}} \times 100, \quad \mathrm{AP}=\frac{\mathrm{AcAP}}{\mathrm{ACAG}+\mathrm{ACAP}} \times 100$

*5 式料寒天に対する\%

第 6 表 $\mathrm{AG}$ と $\mathrm{AP}$ の分離

(刘無水物\%)

\begin{tabular}{|c|c|c|c|c|c|c|c|c|c|c|c|c|c|c|c|}
\hline \multirow{2}{*}{ テ } & \multirow{2}{*}{$\not ゙ サ^{* 1}$ 寒 天 } & \multirow{2}{*}{ 扊 分 } & \multirow{2}{*}{$\begin{array}{c}\text { 扊分中 } \\
\mathrm{SO}_{8}\end{array}$} & \multicolumn{2}{|c|}{ AcAgar } & \multicolumn{2}{|c|}{$A c A G$} & \multicolumn{2}{|c|}{$\mathrm{AcAP}$} & \multicolumn{2}{|c|}{ 比羊*6 } & \multicolumn{2}{|c|}{$\mathbf{A G}$} & \multicolumn{2}{|c|}{ AP } \\
\hline & & & & 收率*4 & $\mathrm{CH}_{8} \mathrm{CO}$ & 收指"5 & $\mathrm{CH}_{s} \mathrm{CO}$ & 驱棉*5 & $\mathrm{CH}_{3} \mathrm{CO}$ & AG & AP & 収率*4 & 戻分 & 收悹*4 & 灭分 \\
\hline & $A * 2$ & 3.4 & 1.2 & 118 & 25 & 63 & 27 & 26 & 25 & 70 & 30 & 54 & 1.1 & 29 & 5.5 \\
\hline & $B * 3$ & 7.6 & 1.3 & 112 & 25 & 72 & 27 & 21 & 23 & 77 & 23 & 53 & 1.1 & 3) & 4.4 \\
\hline
\end{tabular}

*1 供誈原落は高岡産マクサ

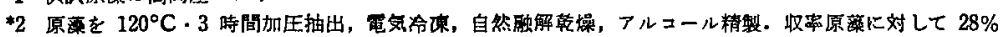

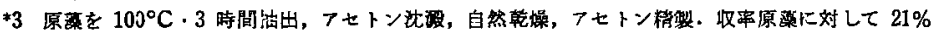

*4 碃製害天に対する \%

*5 アセチル化然天に対する \%

$*_{6} \mathrm{AG}=\frac{\mathrm{AcAG}}{\mathrm{AcAG}+\mathrm{AcAP}} \times 100 \quad \mathrm{AP}=\frac{\mathrm{AcAP}}{\mathrm{AcAG}+\mathrm{AcAP}} \times 100$

イラー標準節 32 メッシュ）1.5〜6 g 岁冷却器と㨨拌棒 をつけた $500 \mathrm{~m} l$ 三頚フラスコにとり, $7 N \mathrm{NaI} 100 \mathrm{~m} l$ を加え, $60^{\circ} \sim 70^{\circ} \mathrm{C} て ゙ 7$ 時間䩀捧しながら加温する。遠 心分離 $\left(3500 \mathrm{rpm} \cdot 10\right.$ 分） L, 溶液部 $\left(F_{1}\right)$ と沈搌部 $\left(\mathrm{P}_{1}\right)$ とに分ける。 $\mathrm{P}_{1}$ は少量の $2.8 N \mathrm{NaI}$ 溶液に照摆し て遠心分雖し(沈澱 $\left.\mathrm{P}_{2}\right)$, この上澄液 $\left(\mathrm{F}_{2}\right)$ を $\left(\mathrm{F}_{1}\right)$ と合 わせて 2.5 倍量の $95 \%$ エタノール中に激しく㨨拌しな がら注入し, 生じる白色の沈溉を四引沪過し, 冷水に溇 濁させてから 2.5 倍量の $95 \%$ エタノールを加兄て沈搌 させ吸引沪過する操作を繰返して NaI を完全に除去し てから，フセトンで処理吸引沪過後真空デシケーター中 で $40^{\circ} \mathrm{C}$ 以下で乾燥させた (AG)。また $\mathrm{P}_{2}$ についても 同様に処理した (AP)。結果は第 7 表のようである。

(3) ジメチルスルホキシド (DMSO) 法

田川らの方法 ${ }^{56}$ ) 亿準して行なった。試料粉末寒天 (タ

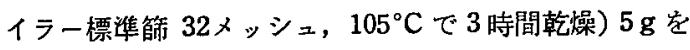
前記の $500 \mathrm{~m} l$ 三頸フラスコにとり，DMSO $250 \mathrm{~g}$ を
加え $70^{\circ} \mathrm{C} て ゙ 3$ 時間加温したのち，遠心分䜅 $(3500 \mathrm{rpm}$ 20 分）して溶液部 $\left(F_{1}\right)$ と沈澱部 $\left(P_{1}\right)$ とに分けた。 $P_{1}$ をもとの三頸フラスコにもどし，新たに DMSO $125 \mathrm{~g}$ を加えて $70^{\circ} \mathrm{C} て ゙ 1$ 時間加温した。同漛にして溶液部 $\left(\mathrm{F}_{2}\right)$ と沈澱部 $\left(\mathrm{P}_{2}\right)$ に分離し， $\mathrm{P}_{2}$ についてさらに DMSO $125 \mathrm{~g}$ を加えて $70^{\circ} \mathrm{C}$ で 1 時問加温し, 溶液部 $\left(F_{8}\right)$

第 7 表 $\mathrm{NaI}$ 法による $\mathrm{AG}$ と $\mathrm{AP}$ の分離

（対無水物\%)

\begin{tabular}{|c|c|c|c|c|c|c|}
\hline \multirow{2}{*}{ 試料察天 } & \multicolumn{3}{|c|}{$\mathrm{AG}$} & \multirow{2}{*}{$\begin{array}{l}\text { AP } \\
\text { 仅策 }\end{array}$} & \multirow{2}{*}{$\frac{\text { 比 }}{A G}$} & \multirow{2}{*}{$\frac{\text { क* }}{\mathrm{AP}}$} \\
\hline & 収事 & 全 $\mathrm{SO}_{8}$ & 灰分 & & & \\
\hline$\nabla \Rightarrow \forall$ & 74 & 1.0 & 3.1 & 11 & 87 & 13 \\
\hline$t=ク+$ & 70 & 1.4 & 2.5 & 9 & 89 & 11 \\
\hline$オ=0,1$ & 95 & 1.7 & 4.1 & 2 & 98 & 2 \\
\hline 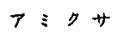 & 81 & 1.1 & 3.3 & 6 & S3 & 7 \\
\hline . & $\mathbf{A G}$ & & & $\frac{\mathrm{A}}{\mathrm{AG}}$ & 90 & \\
\hline
\end{tabular}


第 8 表 $\mathrm{DMSO}$ 法による $\mathrm{AG}$ と $\mathrm{AP}$ の分離

（対然水物\%)

\begin{tabular}{|c|c|c|c|c|c|c|}
\hline \multirow{2}{*}{ 䎄料寒天 } & \multicolumn{3}{|c|}{$\mathrm{AG}$} & \multirow{2}{*}{$\begin{array}{l}\text { AP } \\
\text { 收率 }\end{array}$} & \multicolumn{2}{|c|}{ 比 率* } \\
\hline & 収率 & 全 $\mathrm{SO}_{8}$ & 戻分 & & $A G$ & $\mathrm{AP}$ \\
\hline オゴノリ & 96 & 1.6 & 1.8 & 3 & §7 & 3 \\
\hline$\nabla \eta \#$ & 57 & 0.7 & 1.2 & 37 & 61 & 39 \\
\hline & $\frac{\mathrm{AG}}{\mathrm{G}+\mathrm{A}}$ & & & $\frac{\mathrm{AP}}{\mathrm{AG}}$ & 100 & \\
\hline
\end{tabular}

と沈测部 $\left(\mathrm{P}_{3}\right)$ に分雖した。 $\left(\mathrm{F}_{1}\right) ，\left(\mathrm{~F}_{2}\right) ，\left(\mathrm{~F}_{8}\right)$ を合わせて 4 倍量のアセトン中に激しく㨨拌しながら加え白色沈澱 をえた。これを吸引沪過してセトンで処理して真空デシ ケーター中で乾燥し白色粉末 $(\mathrm{AG})$ 索得た。 $\mathbf{P}_{8}$ につい ても同様にして黄褐色粉末 (AP) を得た。結果は第 8 表 のようである。

以上のように分雖法によって相互の間に AG と AP の比率にかなりの差が認められた。すなわち AG と AP の比率が、クサの場合は Ac 法 $59: 41, \mathrm{NaI}$ 法87 : 13, DMSO 法 $61: 39$ で，フルカリ処理オゴノリの場合は Ac 法 $81: 19$, NaI 法 $98: 2$, DMSO 法 $97: 3$ であっ た。これは寒天の不均一性の問題とその分䧼法にな打研 究の余地のあることを示している。すなるち寒天とくに AG および AP の化学構造の究明と，上記のような溶 解性だけにもとづく分雖法でなく，化学構造にもとづく 分離法の研究が望まれる。
(4) AG 中の D-ガラクトース (Ga) および 3,6-フソ ヒドローLーガラクトース（AnGa）の定量

YAPHE の方法 ${ }^{12}$ に従って，レゾルシノールによる AnGa の定量と, アンスロンによる Ga と AnGa の同 時定量と実施した。反応怯試騟管 $(25 \mathrm{~mm} \times 200 \mathrm{~mm}$ ) を用い, $80^{\circ} \pm 5^{\circ} \mathrm{C}$ の恒温水槽中で行ない，比色計は島 津製スペクトロニック20を使用した。

試料溶夜は $\mathrm{AG}$ を $\mathrm{P}_{8} \mathrm{O}_{0}$ を入れた真空デシケーター 中で減压下 $40^{\circ} \mathrm{C}$ に扔いて 72 洔間以上保って充分乾燥 したものを, $80^{\circ} \mathrm{C}$ で溶解後稀釈して $50 \mathrm{r} / 2 \mathrm{~m} l$ のもの を調製した。

標準 $\mathrm{Ga}$ としては特級品（半井化学薬品会社）を使用 し, 標準溶液 $50 r / 2 \mathrm{~m} l$ とした。

標準 AnGa としては市販粉末寒天をメルカプトリシ ス $^{18)}$ して，3，6-フンヒドロ-レーカ゚ラクトース・ジエチル メルカプタール（細い針状結晶, 融点 $110^{\circ} \mathrm{C}$ ) を得, こ

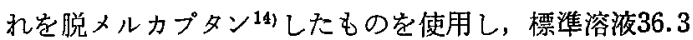
$r / 2 \mathrm{~m} l$ とした。

$\mathrm{Ga}$ と AnGa の計算には YAPHE ${ }^{18)}$ の提案した式を採 用した。

得られた結果は第 9 表のようで，大略 $\mathrm{AnGa}$ 含有量 証 $44 \sim 45 \%$ ，Ga 含有量は 49 50\%，灰分は $2 \%$ で， 荒本 ${ }^{15}$ が指摘した結果とほぼ同様であった。

4. 赤外線吸收スペクトル (IR) の測定

近年マクサおよびオゴノリの寒天について IR が測定

第 9 表 $\mathrm{AG}$ 中の $\mathrm{AnGa}$ と $\mathrm{Ga}$ の分析

（対然水物\%)

\begin{tabular}{|c|c|c|c|c|c|c|c|c|c|}
\hline \multirow{2}{*}{ 供 } & 碔 & \multirow{2}{*}{ 天 } & \multirow{2}{*}{ 分 離 法 } & $\mathrm{AG}$ & \multicolumn{2}{|c|}{ 中の含有 典 } & \multirow{2}{*}{$\begin{array}{c}\mathrm{AnGa} \text { と } \mathrm{Ga} \\
\text { のモル比*2 }\end{array}$} & \multirow{2}{*}{$\begin{array}{c}\text { 欧 分 } \\
\text { (d) }\end{array}$} & \multirow{2}{*}{$\begin{array}{c}\text { 合 計 } \\
\text { (c) }+ \text { (d) }\end{array}$} \\
\hline & 实 & & & AnGa (a) & $\mathrm{Ga}(\mathrm{b})$ & 計（c） & & & \\
\hline \multirow[t]{4}{*}{$\checkmark$} & $\Rightarrow$ & サ & Ac & 44.4 & 50.4 & 94.8 & 0.99 & 2.1 & 96.9 \\
\hline & $\prime \prime$ & & DMSO & 45.0 & 49.4 & 94.4 & 1.03 & 1.2 & 95.6 \\
\hline & $\prime \prime$ & & $\mathrm{NaI}$ & 45.1 & 50.2 & 95.3 & 1.01 & 3.1 & 98.4 \\
\hline & $\prime \prime$ & $($ 精)*1 & Ac & 47.5 & 47.8 & 95.3 & 1.12 & 1.3 & 96.6 \\
\hline \multirow[t]{3}{*}{ t } & $=7$ & \# & Ac & 44.0 & 46.3 & 90.3 & 1.07 & 2.4 & 92.7 \\
\hline & $\prime \prime$ & & $\mathrm{NaI}$ & 45.2 & 49.9 & 95.1 & 1.02 & 2.5 & 97.6 \\
\hline & $\prime \prime$ & (袢) & Ac & 46.1 & 50.5 & 96.6 & 1.03 & 2.4 & 99.0 \\
\hline \multirow[t]{4}{*}{ オ } & $=1$ & y & Ac & 44.6 & 49.4 & 94.0 & 1.02 & 1.6 & 95.6 \\
\hline & $" \prime$ & & DMSO & 43.9 & 50.2 & 94.1 & 0.93 & 1.8 & 95.9 \\
\hline & $" \prime$ & & $\mathrm{Nal}$ & 47.8 & 46.5 & 94.3 & 1.16 & 4.1 & 98.4 \\
\hline & $\prime \prime$ & (䄇) & Ac & 44.8 & 49.7 & 94.5 & 1.01 & 1.8 & 96.3 \\
\hline \multirow[t]{2}{*}{7} & $\$ \quad \eta$ & + & $\mathrm{NaI}$ & 45.2 & 47.6 & 92.8 & 1.07 & 3.3 & 96.1 \\
\hline & $\prime \prime$ & (精) & $\mathrm{Ac}$ & 44.6 & 49.1 & 937 & 1.02 & 1.8 & 95.5 \\
\hline
\end{tabular}

*1 精塰したもの

*2 - $-\frac{\text { (a) }}{144}:-\frac{\text { (b) }}{162}$-を求めた 


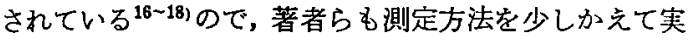
験した。

測定方法： $20 \mathrm{~cm} \times 20 \mathrm{~cm}$ のガラス板を弥溜水でよく 洗浄したのち，この上に蒸溜水中に 1 週間 $(2$ 日に 1 回 水をかえる）浸漬して可溶性物質を除いたセロフォンを はりつけ，さらにこの上に厚さ $1.5 \mathrm{~mm}$ のガラス製わ く（わく内は $5 \mathrm{~cm} \times 7 \mathrm{~cm}$ ) をおく。約 $1 \%$ 試料溶液を ふちのほうから静かにこのなかに流し込み，ガラス製わ くから少し盛り上がる程度にする。放置して寒天膜と し $45^{\circ} \mathrm{C}$ 通風乾燥器中で乾燥する。充分乾燥すると寒天 フィルムはセロファンにぴったり密着する。寒天フィル ムとフィルムに密着したセロフォンの裹側の両 方炕蒸溜水を吹きかけ，フィルムのふちを注意 哚くはがしセロフォンを除く。その後紙製ホル ダーに張り付け，これを $\mathrm{P}_{2} \mathrm{O}_{5}$ 入れたデシケー ター中で 3 日間乾嬠する。このようにして調製 した寒天膜について赤外線分光光度計光研 DS 301 型（日本分光工葉 K K ）を使用して IR を 測定した。

マクサ，オニクサ，フミクサ，オゴノリ（フ ルカリ処理) の4 種の寒天はいずれもほぼ同様 な IR 杂し既報と大差はなかった。第1図お よび第2図にオニクサとアミクサの寒天の IR を示した。また AG と AP についても，その 純度についてはその分離法とともに検討它要す るが，同粶沉して IR を測定したところ，大体 において類似していて相互に少しずつ差が認め られたので，定性的ではあるが第 10 表にその 状態を示した。
要約

マクサ，オニクサ，フミクサおよびオゴノリから寒天 を調製して，それらの寒天からてセチル化法，ヨウ化ナ トリウム法およびジメチルスルホキシド法によって AG とAPを分離した。

原澡の種類, 寒天の調製法および $\mathrm{AG}$ と $\mathrm{AP}$ の分雖 法によって，AG と AP の含有比率にかなりの差が認 められた。

得られた $\mathrm{AG}$ の D-ガラクトースと 3,6-アンヒドロー レーガラクトースの含有量は，それぞれ約 49～50\% およ

WAVE LENGTH $(\mu)$

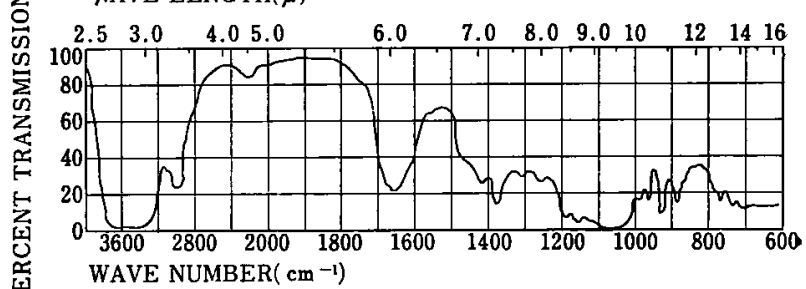

第 1 図 オニクサ寒天の赤外線吸収スペクトル

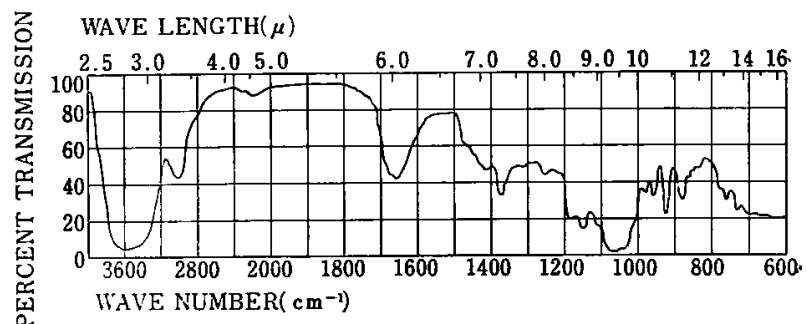

第 2 図 アミクサ寒天の赤外線吸收スペクトル

第 10 表 IR 測定結果

\begin{tabular}{|c|c|c|c|c|c|}
\hline 詺 & 料 & 寒 & 天 & AG $ょ ょ \mho ̛$ AP & 試料寒天の IR との差 \\
\hline オ & $=$ & , & $\mathfrak{y}$ & $\begin{array}{l}\text { AG }\left\{\begin{array}{l}\text { Ac 法 } \\
\text { DMSO 法 } \\
\text { NaI 法 }\end{array}\right. \\
\text { AP DMSO 法 } \\
\text { AG }\left\{\begin{array}{l}\mathrm{Ac} \text { 法 } \\
\mathrm{NaI} \text { 法 }\end{array}\right. \\
\text { AP } \mathrm{NaI} \text { 法 } \\
\text { AG }\left\{\begin{array}{l}\text { Ac 法 } \\
\text { DMSO 法 }\end{array}\right. \\
\text { AP DMSO 法 }\end{array}$ & 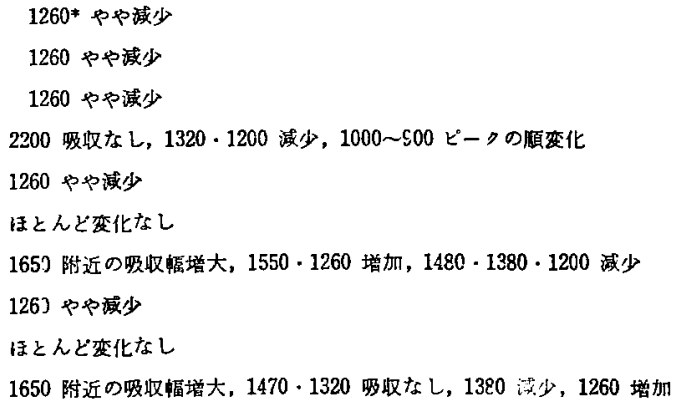 \\
\hline
\end{tabular}

*波数 $1260 \mathrm{~cm}^{-1}$ 
び 44〜45\%であった。

寒天，AG および AP の赤外線吸収スペクトルは相互 に類似していた。

終わりに䧗み，試料原藻について御配虑いただいた忮 阜県寒天碓究所原田典宜氏，ならびに実験に協力された 市川俊治・粕淵芸和・山崎弘志の諸君に感謝する。なお 本研究の一部ほ辳林漁業試験研究費補助金の援助によっ て実施したので記して謝意を表する。

\section{文献}

1) 泉 邦彦・平瀬 進：第 40 回日本生化学大会講演 (1967).

2) 荒术長次：Bull. Chem. Soc. Japan, 29, 543 (1956).

3）荒不長次：日化, 58, 1338 (1937).

4) 勝浦嘉久次・布施恒明 - 狩野和夫：工化，68，205 (1965).

5）田川炤治：水大研報，14，165（1966）。
6）田川昭治・小島良夫：水大研報，15，11（1966）。

7) 布施恒明 - 勝浦嘉久次：工化， 70，724（1967）.

8) HJerten, S.: Biochem. Biophys. Acta, 53, 514 (1961); 62, 445 (1962); 79, 393 (1964).

9) 林 金雄 - 平光 武 - 中村武司：農化，43，699 (1969).

10）林 金雄・永田幸雄：食品工誌，14，450（1967）.

11）林 金雄 - 安本值人：岐大農研報, 22, 131 (1966).

12) Yaphe, W.: Anal. Chem., 32, 1327 (1960).

13）荒木長次 - 平瀬 進：Bull. Chem. Soc. Japan, 26, 463 (1953).

14) YAPHE, W.: Nature, 183, 44 (1959).

15) 荒木長次： Proc. of Fifth Intern. Seaweed Symposium (1965).

16) Tsuchiy A, Y. and Hong, K. C.: Tohoku, J. Agr. Research, 16, 141 (1965).

17）布施恒明・徳間洋二・勝浦嘉久次：農化，42558 (1968).

18）田川昭治：水産大研報，17，76（1968）。

(1970 年 7 月 29 日受理) 